\title{
Plurihormonal pituitary macroadenoma: a case report
}

\author{
Ebtesam Allehaibi ${ }^{1 *}$, Mussa H. AlMalki ${ }^{1,2}$ and Imad Brema ${ }^{1}$
}

\begin{abstract}
Background: Plurihormonal pituitary adenomas are a unique type of pituitary adenomas that secrete two or more pituitary hormones normally associated with separate cell types that have different immunocytochemical and ultrastructural features. Although they represent $10-15 \%$ of all pituitary tumors, only a small fraction of plurihormonal pituitary adenomas clinically secrete multiple hormones. The most common hormone combinations secreted by plurihormonal pituitary adenomas are growth hormone, prolactin, and one or more glycoprotein hormones. The most common hormonal symptom is acromegaly (50\%). The aim of this case report is to bring awareness about this rare type of pituitary adenomas and to describe the unique presentation of our patient, even though plurihormonal pituitary adenomas are known mostly as a clinically silent tumors.
\end{abstract}

Case presentation: Herein, we describe an unusual case of plurihormonal pituitary adenoma with triple-positive staining for adrenocorticotropic hormone, growth hormone, and prolactin. The patient is a 65-year-old Egyptian woman who presented with mass effect symptoms of the pituitary tumor, which primarily manifested as severe headache and visual field defects. She also presented with some cushingoid features, and further analysis confirmed Cushing's disease; slightly high prolactin and normal growth hormone levels were observed. She underwent transsphenoidal surgery and has been in remission thus far. Only a few cases have been reported in the literature, but none has exhibited silent acromegaly or mass effect symptoms as the initial presentation.

Conclusion: This case highlights an unusual plurihormonal pituitary adenoma case with a rare combination of secreted hormones; mass effect symptoms were dominant, as were uncommon visual field defects. Our case further proves that immunohistochemical analyses of all pituitary hormones are needed to ensure correct diagnosis and to alert clinicians to the need for more rigorous follow-up due to the higher morbidity of these patients. Our case report approval number Federal Wide Assurance NIH, USA is FWA00018774 IRB registration number with OHRP/NIH is IRB00010471.

Keywords: Plurihormonal pituitary adenoma, Nonfunctioning, Silent pituitary adenomas, Silent somatotroph adenomas, Silent gonadotroph, Silent corticotroph

\section{Background}

Plurihormonal pituitary adenomas (PHAs) are a unique type of pituitary adenoma that are further divided into two main groups: monomorphous adenoma of one

*Correspondence: esallehaibi@gmail.com

1 Obesity, Endocrine, and Metabolism Center, King Fahad Medical City, Riyadh, Saudi Arabia

Full list of author information is available at the end of the article cell type producing different hormones or bi- or plurimorphous adenoma of two or more cell types producing different hormones [1]. They represent $10-15 \%$ of all pituitary tumors, but only a small number clinically secretes multiple hormones. PHAs could be either functioning tumors, having symptoms related to one or more hormones secreted by the adenomas, or nonfunctioning tumors [2-4]. original author(s) and the source, provide a link to the Creative Commons licence, and indicate if changes were made. The images or other third party material in this article are included in the article's Creative Commons licence, unless indicated otherwise in a credit line to the material. If material is not included in the article's Creative Commons licence and your intended use is not permitted by statutory regulation or exceeds the permitted use, you will need to obtain permission directly from the copyright holder. To view a copy of this licence, visit http://creativecommons.org/licenses/by/4.0/. The Creative Commons Public Domain Dedication waiver (http://creativeco mmons.org/publicdomain/zero/1.0/) applies to the data made available in this article, unless otherwise stated in a credit line to the data. 
The most common hormone combinations secreted by PHAs are growth hormone $(\mathrm{GH})$, prolactin (PRL), and one or more glycoprotein hormones. The most common hormonal symptom is acromegaly (50\%), followed by subclinical Cushing's disease, then symptoms related to hyperprolactinemia [5].

Careful follow-up of patients with PHA is essential owing to the high risk of tumor recurrence as compared with tumors that secrete only one hormone $[1,6]$. This report describes an unusual case of pituitary adenoma presenting with features of Cushing's disease, and the resected tumor revealed triple hormonal staining for $\mathrm{ACTH}, \mathrm{GH}$, and prolactin.

\section{Case presentation}

A 65-year-old Egyptian woman with a history of type 2 diabetes, hypertension, primary hypothyroidism, and class-III obesity presented acutely to the emergency room (ER) with an intractable headache and blurred vision. She had also recently experienced a worsening of her diabetes control despite being on a basal-bolus insulin regimen. She had no clear-cut cushingoid features apart from central obesity, and she had no family history of pituitary tumors or similar illness. She is a stay-at-home mother to four. Children are all a product of uneventful pregnancies and were delivered normally. She is married for 20 years to a physician. She never smoked or drank alcohol.

Computed tomography (CT) brain imaging and subsequent magnetic resonance imaging (MRI) showed a sellar mass consisting of a pituitary macroadenoma that measured $2.9 \times 1.5 \mathrm{~cm}$ invading the roof of the sphenoid sinuses and compressing the neurophysis and the optic chiasm (Fig. 1). She has central obesity but did not appear cushingoid or acromegalic. Visual field examination revealed left homonymous hemianopia and right homonymous inferior quadrantanopia (Fig. 2A). Initial laboratory investigations revealed elevated corticotropin (ACTH) levels of 33.6 (1.03-10.7) pmol/L, mildly increased prolactin levels of $66.3(5.18-26.53) \mathrm{ng} / \mathrm{ml}$ , normal IGF-1 levels of $17.29(4.68-31.72) \mathrm{nmol} / \mathrm{L}$, and normal GH levels of $0.72(0.18-20.6) \mathrm{mIU} / \mathrm{L}$. The remaining anterior pituitary hormone levels were as follows: FSH was $12.50(4.5-21.5) \mathrm{IU} / \mathrm{L}, \mathrm{LH}$ was 3.5 (9-19) $\mathrm{pmol} / \mathrm{L}$, TSH was 1.441 (2.6-5.7) $\mathrm{mIU} / \mathrm{L}$, and free T4 was $13.1 \mathrm{IU} / \mathrm{L}$ (9-23). Further investigations confirmed Cushing's disease as follows: 24-hour urinary free cortisol was grossly elevated at $391 \mu \mathrm{g} / 24$ hours (6-123), serum cortisol after the $1 \mathrm{mg}$ dexamethasone suppression test was $783 \mathrm{nmol} / \mathrm{l}$ (normal $<50 \mathrm{nmol} / \mathrm{l}$ ). Serum cortisol after the high-dose dexamethasone suppression test was $613 \mathrm{nmol} / \mathrm{l}$ (20\% reduction from baseline). She underwent uneventful transsphenoidal surgery (TSS) for decompression of the optic chiasm, which was successful
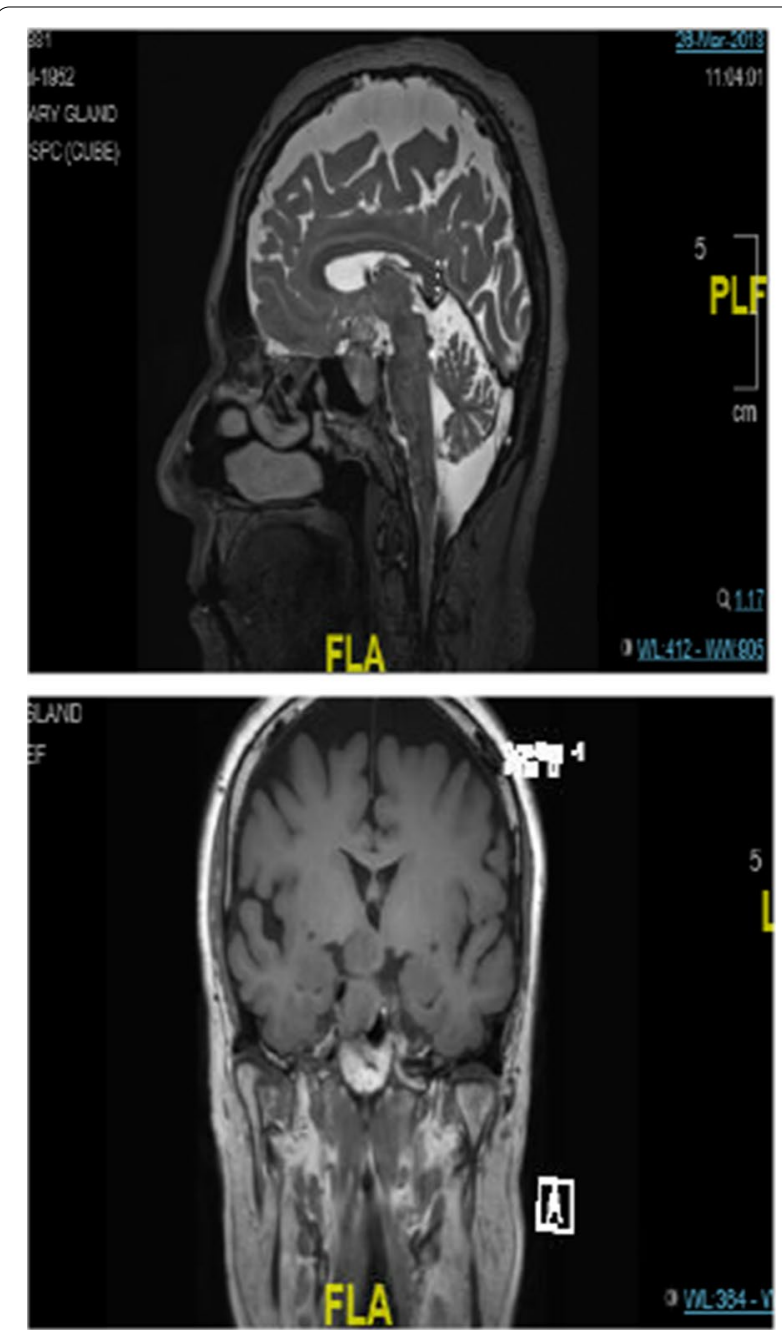

Fig. 1 Baseline magnetic resonance imaging (MRI) pituitary showing a large sellar/suprasellar mass lesion causing compression and superior displacement on the optic chiasm as well as compression and lateral displacement of the neurohypophysis. Erosion of the roof of the sphenoid sinus with subsequent extension is also observed

at normalizing her visual fields; however, residual tumor was still present on follow-up MRI after 3 months (Fig. 3). Interestingly, histology of the resected tissue showed staining for ACTH (Fig. 4), GH (Fig. 5), and PRL (Fig. 6), with a Ki-67 proliferation index of less than $2 \%$. Postoperatively, she experienced symptom resolution with normalization of the visual fields (Fig. 2B). A followup evaluation 12 months postoperatively showed a normal response to the $1 \mathrm{mg}$ dexamethasone suppression test; her cortisol levels were $<27.6 \mathrm{nmol} / \mathrm{L}$, and 24-hour urinary free cortisol was also normal at $177 \mu \mathrm{g} / 24$ hours (21-292). MRI (Fig. 7) pituitary performed 17 months postoperatively showed redemonstration of the residual enhancing lesion seen in the suprasellar region closely 


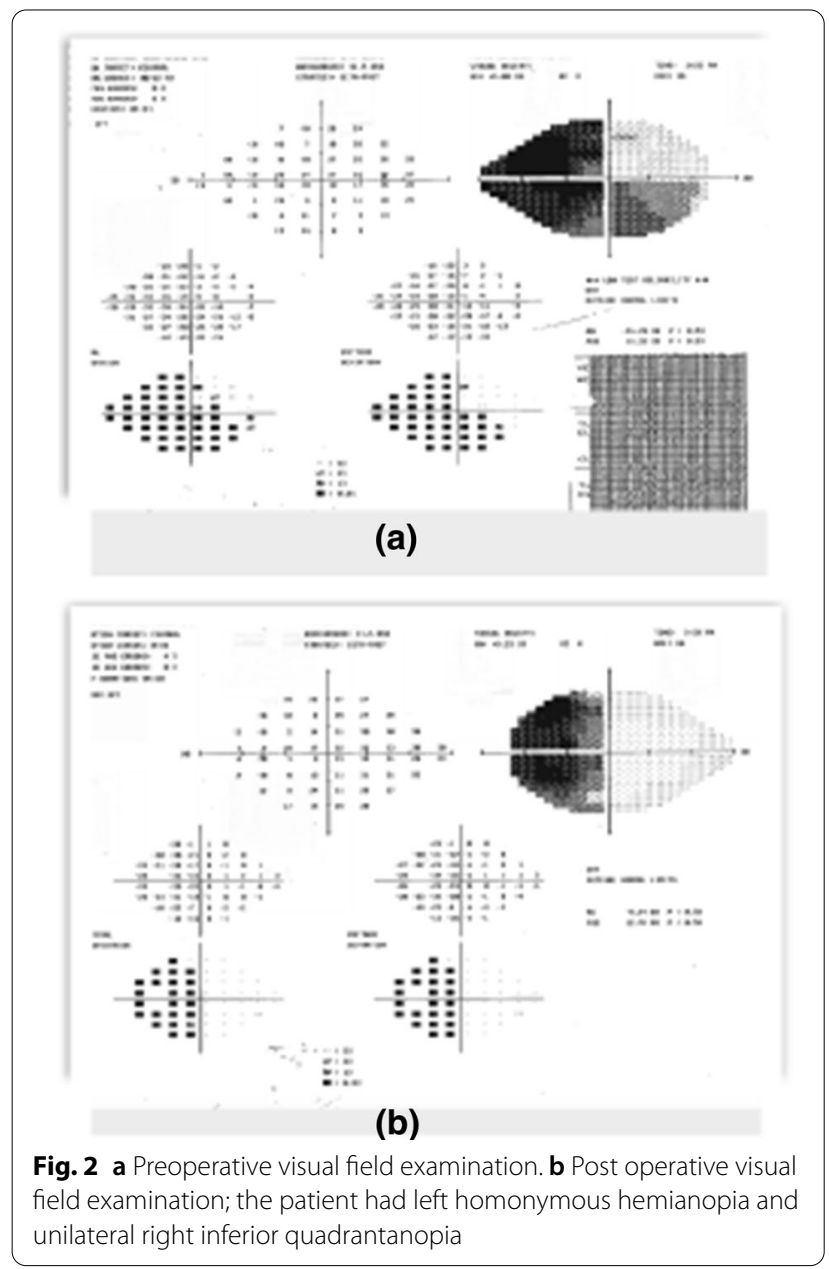

related to the pituitary stalk, which remained stable in size, measuring $12.5 \times 11.5 \mathrm{~mm}$. Her diabetes mellitus and hypertension also became controlled on fewer medications with ability to discontinue insulin therapy. She remained asymptomatic with no biochemical evidence of recurrence 17 months postoperatively, and there was no need for any treatment utilization.

\section{Discussion}

The majority of plurihormonal pituitary adenomas produce GH, PRL, and TSH because somatotroph, lactotroph, and thyrotroph cells all arise from the same progenitor [7]. The expression of pituitary hormones is regulated by several transcription factors: PIT-1 regulates the functional differentiation of $\mathrm{GH}, \mathrm{PRL}$, and TSH; STF-1 and GATA-2 regulate the expression of FSH and $\mathrm{LH}$, while ACTH expression is controlled by T-PIT [7, 8], which might explain the higher association with $\mathrm{GH}$ and PRL cosecretion. PHAs constitute a significant

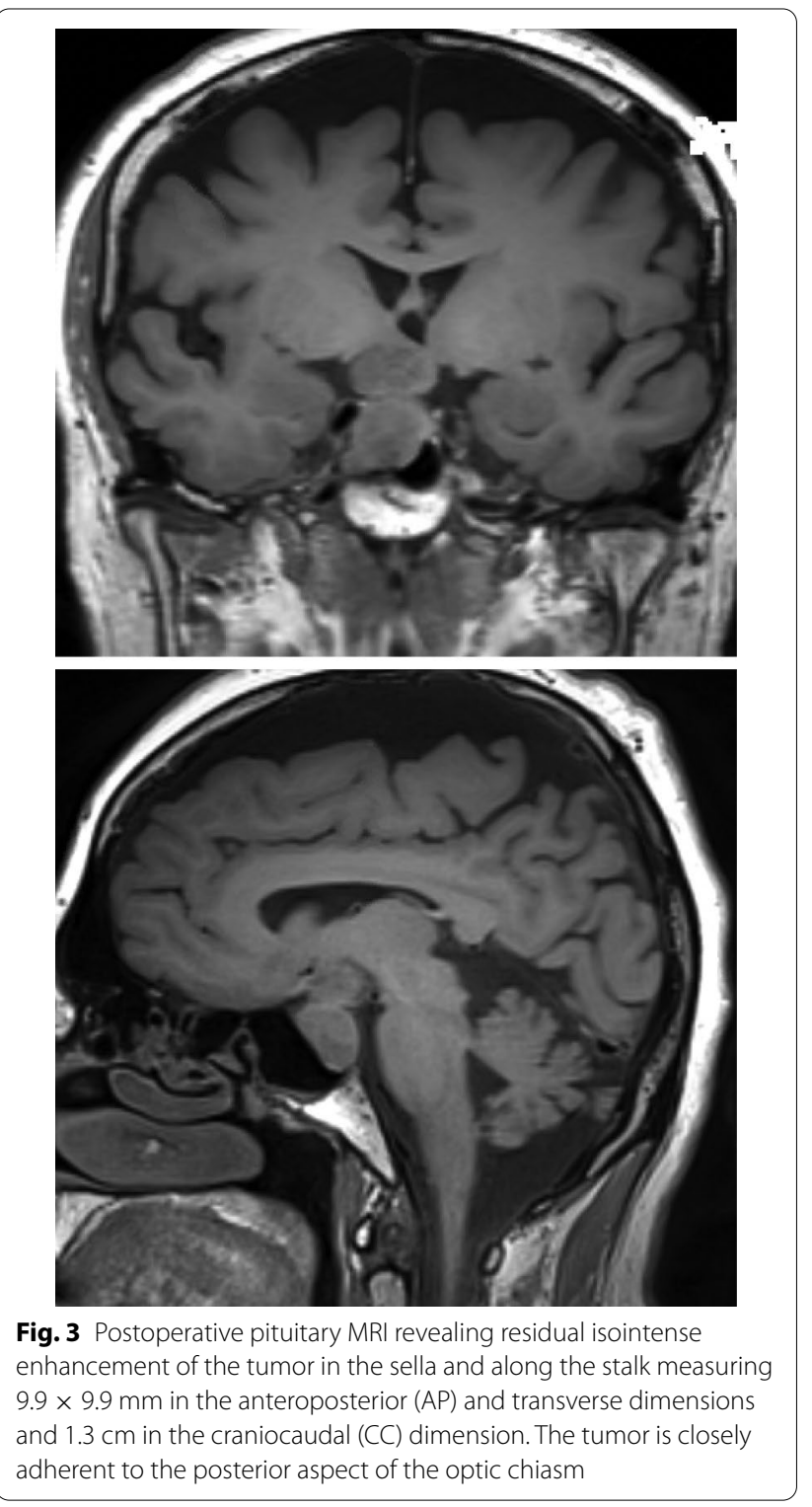

proportion of pituitary adenomas, with a prevalence of approximately $31-36 \%$ of surgically resected tumors [9, 10]. The most frequent associations are with $\mathrm{GH}$ and PRL or LH and FSH [11]. GH-producing adenomas with concomitant ACTH production are extremely rare, although they have been reported previously in a few cases [1220]. Clinically, the majority of PHAs are silent, and diagnosis almost always relies on immunohistochemical analysis of the tumor tissue to demonstrate positivity for unrelated hormones [8, 9]. Roca et al. [20] recently reviewed the literature on PHAs and reported 21 cases with ACTH-GH plurihormonal pituitary adenoma. Of 


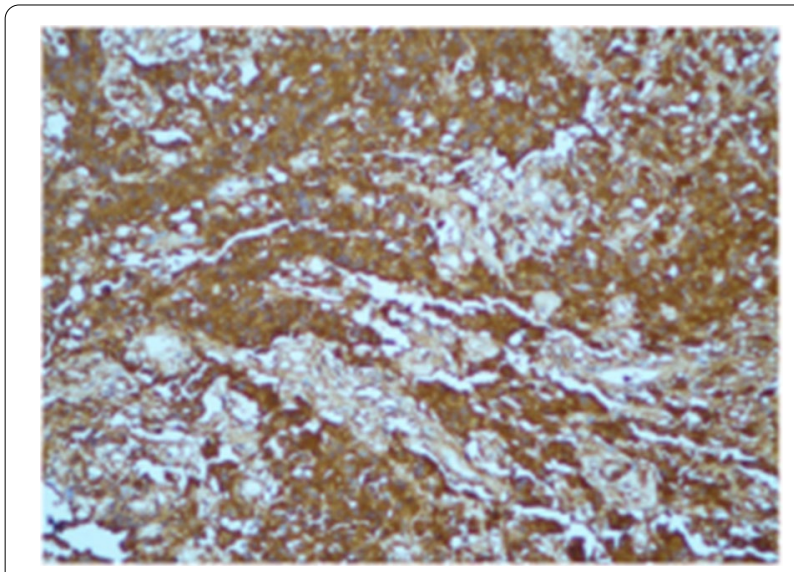

Fig 4 Immunostaining showing positivity for adrenocorticotropic hormone

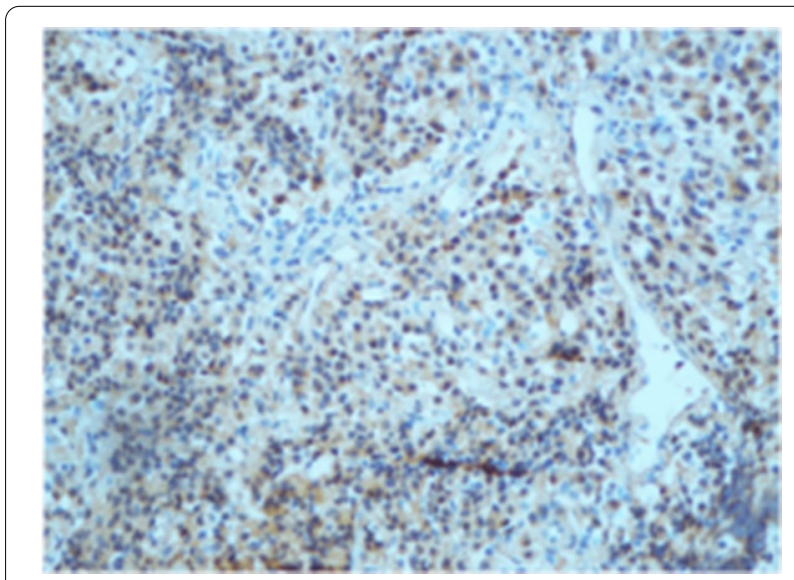

Fig. 5 Immunostaining showing positivity for growth hormone

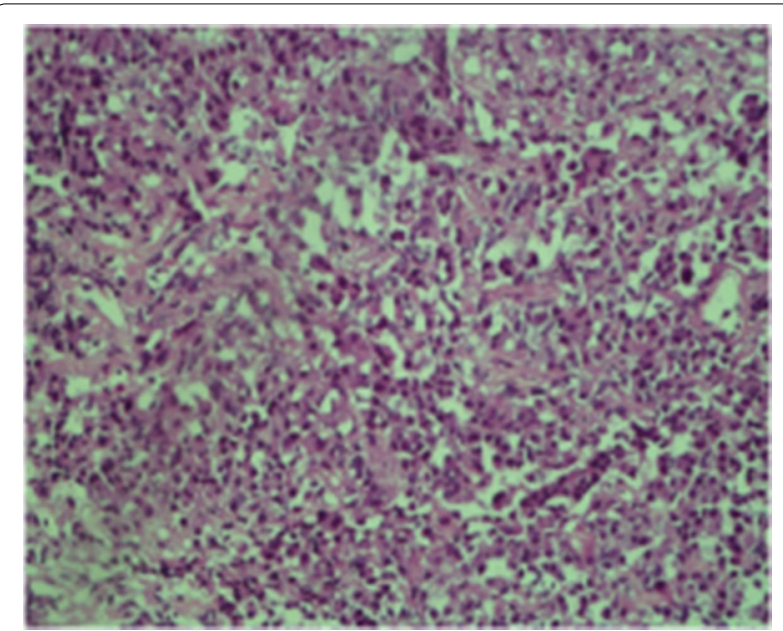

Fig. 6 Immunostaining showing positivity for prolactin these, 2 cases had Cushing's disease, 5 had both acromegaly and Cushing's disease, 11 had signs of acromegaly, and 3 had pituitary apoplexy. Interestingly, they found that six cases had PRL secretion in addition to ACTH and GH. In PHAs, symptoms related to ACTH are uncommon and were observed in only $3.6 \%$ of the reported cases; this phenomenon may be due to insufficient autonomous $\mathrm{ACTH}$ production or the absence of $\mathrm{ACTH}$ production [21-23]. The pathogenesis of plurimorphous plurihormonal tumors is less clearly defined, but it has been suggested that it may result from neoplastic transformation of two separate cell lines or from the transdifferentiation of one single tumor cell line into a different hormoneproducing cell line [8].

In the current study, we present an interesting and rare case of PHA in which the patient had ACTH-producing tumors that clinically manifested as Cushing's disease and showed GH and PRL positivity by immunohistochemistry, both of which were asymptomatic or silent. In contrast to previously published cases where there was a predominant clinical presentation with acromegaly and symptoms of hyperprolactinemia, our patient presented initially with headaches and visual symptoms, as well as with clinical features of Cushing's syndrome in the form of uncontrolled blood pressure, diabetes, obesity, and moon face. Postoperative pituitary MRI scans showed a successful reduction in tumor size with some residual tumor remaining in the sella, leading to the resolution of the biochemical and clinical features of cortisol excess. These rare and unusual PHAs tend to be aggressive and associated with a poor outcome [15]. PHA patients with ACTH cosecretion appear to have a higher rate of tumor recurrence. Careful evaluation of patients with such tumors and strict follow-up regimens are needed owing to the higher morbidity of these patients [15, 24, 25]. Our case adds a significant body of knowledge to the current literature of such rare tumors. However, further studies are needed to elucidate the features and natural history of these PHAs.

\section{Conclusion}

This case highlights an unusual PHA case of a rare pituitary adenoma with cosecretion of ACTH, GH, and PRL. Mass effect symptoms were dominant, along with some cushingoid features. Although PHAs are usually clinically silent tumors, they are not uncommon pituitary adenomas, and immunohistochemical staining for all pituitary hormones is needed to ensure the correct diagnosis and to alert the clinicians to the need for more rigorous follow-up due to the higher morbidity of these patients. 

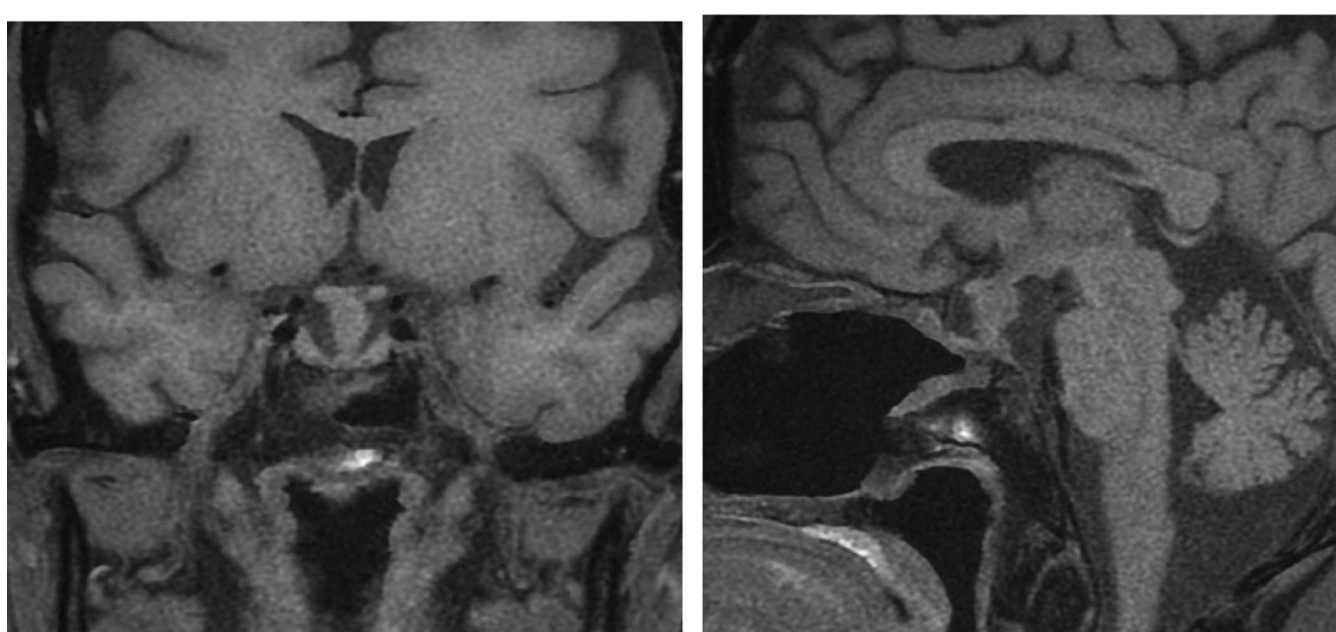

Fig. 7 Last pituitary magnetic resonance imaging (MRI) 15/10/2019. Compared with the previous MRI dated on 15 April 2019, there is redemonstration of the residual enhancing lesion seen in the suprasellar region closely related to the pituitary stalk. Its residual remained stable in size; measures $12.5 \times 11.5 \mathrm{~mm}$ in CC $\times$ AP dimensions in sagittal plane compared with $11.5 \times 11.5 \mathrm{~mm}$ in previous study in same location. No other significant interval changes demonstrated

Further work is required to better understand the pathogenesis of this rare condition.

\section{Abbreviations}

GH: Growth hormone; PRL: Prolactin; ACTH: Adrenocorticotropic hormone; PTHs: Plurihormonal pituitary adenomas; FSH: Follicle-stimulating hormone; TSS: Transsphenoidal surgery.

\section{Acknowledgements}

This case report was presented as a poster presentation at the American Association of Clinical Endocrinologist Gulf Chapter Conference in Dubai, United Arab Emirates, in November 2018 and at the Endocrine Society Meeting in New Orleans, Louisiana in March 2019.

\section{Authors' contributions}

EA: author of the case report; Endocrinology fellow and physician of the patient. IB: editor of the case report; Endocrinology attending and physician of the patient who diagnosed the patient. MA is the pituitary consultant specialist who was consulted for this case and helped manage the patient: he also helped edit the case report. All authors read and approved the final manuscript.

\section{Funding}

No grants were received for this research.

\section{Availability of data and materials}

The datasets used and/or analyzed during the current study are available from the corresponding author upon reasonable request.

\section{Declarations}

\section{Ethics approval and consent to participate}

This study was approved by the institutional review board of King Fahad Medical City, RIYADH, Saudi Arabia. Our case report approval number Federal Wide Assurance NIH, USA is FWA00018774 IRB registration number with OHRP/NIH is IRB00010471.

\section{Consent for publication}

Written informed consent was obtained from the patient for publication of this paper. A copy of the written consent is available for review by the Editorin-Chief of this journal.

\section{Competing interests}

The authors have no conflicts of interests

\section{Author details}

1 Obesity, Endocrine, and Metabolism Center, King Fahad Medical City, Riyadh, Saudi Arabia. ${ }^{2}$ King Fahad Medical City, Faculty of Medicine, King Saud bin Abdul-Aziz University for Health Sciences, Riyadh, Saudi Arabia.

Received: 19 October 2019 Accepted: 7 June 2021

Published online: 29 July 2021

\section{References}

1. Kovaks K, Horvath E, Asa SL, Stefaneanu L, Sano T. Pituitary cells producing more than one hormone human pituitary adenomas. Trends Endocrinol Metab. 1989;1:104-7.

2. World Health Organization. Classification of tumours of endocrine organs. 4th ed. Geneva: World Health Organization; 2017.

3. Mete O, Lopes MB. Overview of the 2017 WHO classification of pituitary tumors. Endocr Pathol. 2017;28:228-43.

4. Inoshita N, Nishioka H. The 2017 WHO classification of pituitary adenoma: overview and comments. Brain Tumor Pathol. 2018;35(2):51-6.

5. Osamura RY, Kajiya H, Takei M, et al. Pathology of the human pituitary adenomas. Histochem Cell Biol. 2008;130(3):495-507.

6. Malchiodi E, Profka E, Ferrante E, Sala E, Verrua E, Campi I, Lania AG, Arosio M, Locatelli M, Mortini P, et al. Thyrotropin-secreting pituitary adenomas: outcome of pituitary surgery and irradiation. J Clin Endocrinol Metab. 2014;99:2069-76.

7. Oki K, Yamane K, Oda Y, et al. Combined acromegaly and subclinical Cushing disease related to high-molecular-weight adrenocorticotropic hormone: case report. J Neurosurg. 2009;110(2):369-73.

8. Kannan S, Staugaitis SM, Weil RJ, et al. Case report: a rare corticotrophsecreting tumor with coexisting prolactin and growth hormone staining cells. Case Rep Endocrinol. 2012. https://doi.org/10.1155/2012/529730. 
9. Tahara S, Kurotani R, Ishii Y, Sanno N, Teramoto A, Osamura RY. A case of Cushing's disease caused by pituitary adenoma producing adrenocorticotropic hormone and growth hormone concomitantly: aberrant expression of transcription factors NeuroD1 and Pit-1 as a proposed mechanism. Mod Pathol. 2002;15(10):1102-5.

10. Tsuchiya K, Ohta K, Yoshimoto T, Dai M, Izumiyama H, Hirata Y. A case of acromegaly associated with subclinical Cushing's disease. Endocr J. 2006;53(5):679-85.

11. Roca E, Mattogno PP, Porcelli T, et al. Plurihormonal ACTH-GH pituitary adenoma: case, report and systematic literature review. World Neurosurg. 2018;114:e158-64.

12. Korkmaz H, Akarsu E, Özkaya M, Öztürk ZA, Tutar E, Araz M. Plurihormonal pituitary adenoma: acromegaly associated with subclinical Cushing's disease. Acta Endocrinol (Buc). 2015. https://doi.org/10.4183/aeb.2015. 389.

13. Melmed S. Pathogenesis of pituitary tumors. Nat Rev Endocrinol. 2011;7:257-66.

14. Ho DM, Hsu CY, Ting LT, Chiang H. Plurihormonal pituitary adenomas: immunostaining of all pituitary hormones is mandatory for correct classification. Histopathology. 2001;39(3):310-9.

15. Pawlikowski M, Kunert-Radek J, Radek M. Plurihormonality of pituitary adenomas in light of immunohistochemical studies. Endokrynol Pol. 2010;61:63-6.

16. Luk CT, Kovacs K, Rotondo F, Horvath E, Cusimano M, Booth GL. Plurihormonal pituitary adenoma immunoreactive for thyroid-stimulating hormone, growth hormone, follicle-stimulating hormone, and prolactin. Endocr Pract. 2012. https://doi.org/10.4158/EP12033.CR.

17. Matsuno A, Sasaki T, Mochizuki T, et al. A case of Cushing's disease presenting with hypersecretion of GH and PRL five years after adrenalectomy. Acta Neurochir. 1996;138:1002.

18. BatisseLignier M, Maqdasy S, Mestre B, Roche B, Chazal J, Tauveron I. An unusual plurihormonal pituitary adenoma. Endocr Abst. 2012;29:1540.
19. Kageyama K, Nigawara T, Kamata Y, Terui K, Anzai J, Sakihara S, Suda T. A multihormonal pituitary adenoma with growth hormone and adrenocorticotropic hormone production, causing acromegaly and Cushing disease. Am J Med Sci. 2002;324(6):326-30.

20. Takiguchi T, Koide $H$, Nagano H, et al. Multihormonal pituitary adenoma concomitant with Pit-1 and Tpit lineage cells causing acromegaly associated with subclinical Cushing's disease: a case report. BMC Endocr Disord. 2017;17(1):54. https://doi.org/10.1186/s12902-017-0203-5.

21. Cooper $\mathrm{O}$, Melmed S. Subclinical hyperfunctioning pituitary adenomas: the silent tumors. Best Pract Res Clin Endocrinol Metab. 2012;26(4):447-60.

22. Korkmaz H, Akarsu E, Özkaya M, Öztürk ZA, Tutar E, Araz M. Plurihormonal pituitary adenoma: acromegaly associated with subclinical Cushing's disease. Acta Endo (Buc). 2015. https://doi.org/10.4183/aeb.2015.389.

23. Dumbrava M, Costinean S, Stancu C, Badiu C. "Mind the gap" in immunohistochemical techniques used in pathology of pituitary adenomas. Acta Endo (Buc). 2005;1 (4):411-22.

24. Saeger W, Ludecke DK, Buchfelder M, Fahlbusch R, Quabbe HJ, Petersenn S. Pathohistological classification of pituitary tumors: 10 years of experience with the German Pituitary Tumor Registry. Eur J Endocrinol. 2007;156(2):203-16.

25. Bradley KJWJ, Turner HE. Non-functioning pituitary adenomas with positive immunoreactivity for ACTH behave more aggressively than ACTH immunonegative tumors but do not recur more frequently. Clin Endocrinol (Oxf). 2003;58(1):59-64.

\section{Publisher's Note}

Springer Nature remains neutral with regard to jurisdictional claims in published maps and institutional affiliations.
Ready to submit your research? Choose BMC and benefit from:

- fast, convenient online submission

- thorough peer review by experienced researchers in your field

- rapid publication on acceptance

- support for research data, including large and complex data types

- gold Open Access which fosters wider collaboration and increased citations

- maximum visibility for your research: over $100 \mathrm{M}$ website views per year

At BMC, research is always in progress.

Learn more biomedcentral.com/submissions 